\title{
Thyroid disorder in pregnancy and postpartum with neonatal outcome a study in tertiary care centre
}

\author{
Bharati Das*, Puspanjali Khuntia
}

Department of Obstetrics and Gynecology, Post-Partum Programme, SCB Medical College and Hospital, Cuttack, Odisha, India

Received: 06 March 2019

Accepted: 30 March 2019

*Correspondence:

Dr. Bharati Das,

E-mail: bharathidas15@gmail.com

Copyright: () the author(s), publisher and licensee Medip Academy. This is an open-access article distributed under the terms of the Creative Commons Attribution Non-Commercial License, which permits unrestricted non-commercial use, distribution, and reproduction in any medium, provided the original work is properly cited.

\section{ABSTRACT}

Background: Thyroid disorders are well known entity in pregnancy. Both mother and baby have to suffer from the consequences. Lot of works has been done and many guidelines too came out over the years but what is actual understanding of the disease process by the mothers about themselves and for their babies especially in developing country like India remained uncovered. This has been analysed in present study.

Methods: It is a prospective observational study done in the post-partum programmed department of SCB medical college and hospital, a tertiary care center in eastern part of India for 3 years period. Thyroid dysfunction of the mothers and new born screening of thyroid function of their babies has been assessed.

Results: During this period total no of the babies along with their mothers were evaluated were 3762 . Total no of thyroid disorders detected in $85(2.25 \%)$ of mothers, among which hypothyroidism in 79 (2.09\%) and hyperthyroidism in $6(0.16 \%)$ were found. From total 85 cases, $79(93 \%)$ mothers were hypothyroid and $6(7 \%)$ were hyperthyroid. Among the hypothyroid mothers $32(40.5 \%)$ were diagnosed before present pregnancy and $(59.5 \%)$ were diagnosed during pregnancy. In the babies of hypothyroid mother, new born screening for thyroid function was done only in $14(17.7 \%)$ cases between 5-10 days.

Conclusions: Thyroid screening should be done in pregnancy as universal screening instead of high-risk cases. Documentation and interdepartmental coordination are very much essential in thyroid disorders for further decision by the physician for necessity of continuation of treatment and thyroid function test in the post-partum period for the mothers and its long-term consequences. It also guides the neonatologist or pediatrician doing thyroid function test of their babies. Ideally All newborns should be screened for congenital hypothyroidism as a part of new born screening (NBS) programmed. Effective communication with the mother and the family is very much essential for monitoring and treatment of both mother and the baby.

Keywords: Hyperthyroidism, Hypothyroidism, Newborn, Post- partum, Pregnancy

\section{INTRODUCTION}

Thyroid disorders are well known entity in pregnancy. Both hypothyroid and hyperthyroid whether subclinical or overt, can cause problem in mother and in the baby. ${ }^{1-8}$ Timely detection and treatment will definitely reduce the outcomes of the pregnancy, fetus and of the neonate. This can happen only when the mother and the family understand this. As each pregnancy, delivery, neonatal care is managed by different specialists at different places and in different times, documentation and personal communication are very much essential. Over the time though lot of works and guideline has been released but post-partum aspects still remained mostly uncovered part 
and also not very clear. In present study authors tried to focus on it. ${ }^{9-13}$

\section{Physiology}

Thyroid metabolism in pregnancy is operated by 3 component model. Hypothalamic pituitary axis in woman, placenta and fetal hypothalamic pituitary axis. ${ }^{1}$ Maternal hyperplasia of thyroid gland occur in pregnancy with $10 \%$ increase in size. During $1^{\text {st }}$ trimester usually between $7^{\text {th }}-11^{\text {th }}$ week there is increase in HCG which stimulate the TSH receptor due to structural similarity with TSH, cause transient increase in thyroid hormone production and partial suppression of TSH. Estrogen causes increase in thyroid binding globulin. Increased renal excretion of thyroxine, placental deiodination of thyroxine and transfer of thyroxine to the fetus leads to transient thyroid deficiency. ${ }^{2}$ Functioning of fetal thyroid occurs at $10^{\text {th }}-12^{\text {th }}$ weeks of gestation but get mature by third trimester. Till then the fetal metabolic requirements are met by maternal thyroxine. ${ }^{14}$

\section{METHODS}

A prospective observational study done in the postpartum programmed department of SCB Medical College and hospital, a tertiary care center in eastern part of India from February 2016 to January 2019. From our previous experience, on random enquiry during process of checking the baby prior to immunization, came to know many mothers were having hypothyroidism and many were also not aware of it and thyroid screening of the babies were also not done. So, from February 2016, before routine immunization at $6^{\text {th }}$ weeks, $10^{\text {th }}$ weeks, $14^{\text {th }}$ weeks as a regular process, authors tried to check the records of the baby and the mother. Along with-it maternal understanding of thyroid dysfunction on them and on their babies had been assessed verbally. Postpartum thyroid function test was advised to the mothers in which post-partum screening at $6^{\text {th }}$ weeks were not done previously. Similarly, for the babies of hypothyroid and hyperthyroid mothers in which newborn screening was not done, thyroid function test was advised. Any abnormal reports of the mother or child has been sent to endocrinology OPD for further management as well as continuation of their follow up along with immunization at post-partum programmed department.

\section{Exclusion criteria}

- Mothers with only type II DM or GDM were excluded from the study

- Newborn babies brought for birth dose immunization were also excluded from the study.

As most of the babies were brought by the relatives who were ignorant about the maternal condition and babies too were under supervision by the physicians of the institute from where they were brought. However, the relatives were advised to get necessary documents of the mother and baby on their next immunization visit.

\section{RESULTS}

During this period total no of the babies along with their mothers were evaluated are 3762. Total no of thyroid disorders detected in $85(2.25 \%)$ of mothers, among which hypothyroid $(2.09 \%)$ and hyperthyroid $(0.16 \%)$. From total 85 cases, $79(93 \%)$ mothers were hypothyroid and $6(7 \%)$ were hyperthyroid. Among the hypothyroid mothers $32(40.5 \%)$ were diagnosed before present pregnancy and $53(59.5 \%)$ were diagnosed during pregnancy by single TSH screening (Figure1).

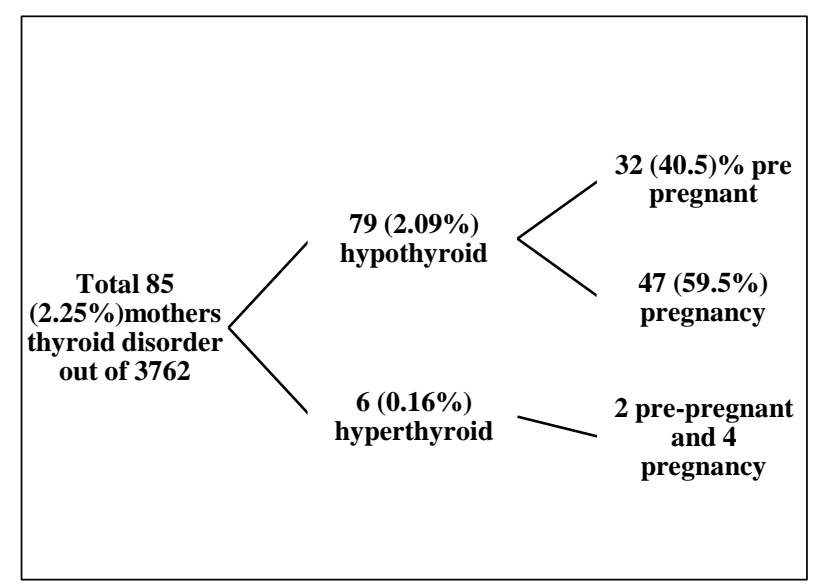

Figure 1: Distribution of thyroid disorders in pregnancy.

Out of which 61 mothers were gravida 1 (G1) and 18 mothers were multigravida. In the Pre-pregnancy group hypothyroidism was diagnosed on evaluation, in which previous pregnancy loss were found in 10 cases, primary infertility in 6 cases in which 1 mother went for IVF, leg swelling in 14 cases, menstrual abnormality and leg swelling requiring blood transfusion in one and neck swelling in one.

Gestational diabetes mellitus (GDM) was found in 5 cases, gestational hypertension 4cases, PROM in 2 cases, APH in 1 case. Thyroxine taken by the mothers during pregnancy were $25 \mathrm{mcg}-10,37.5 \mathrm{mcg}-1,50 \mathrm{mcg}-41,75 \mathrm{mcg}-$ $9,88 \mathrm{mcg}-1,100 \mathrm{mcg}-9,125 \mathrm{mcg}-7,150 \mathrm{mcg}-1$. Out of 32 pre pregnant mothers 6required increased dose, 6 required decreased dose and 32 continued with same dose. Only 1 mother was having $25 \mathrm{mcg}$ thyroxine, 11 mothers $50 \mathrm{mcg}$, and 20 mothers the thyroxine was more than $50 \mathrm{mcg}$. In the hyperthyroid group from 6 cases, pre-pregnancy diagnosis was made in 2 cases and 4 were during pregnancy. Among which 2 were found to be having Graves' disease, 1 case was pre pregnancy hypothyroid to hyperthyroid in pregnancy due to irregular follow up, other 3 cases no documents were found. 2 pre-pregnancy cases received Neomercazole before present pregnancy. All cases were under the supervision of endocrinologist during pregnancy and received Propyl-thio-uracil (PTU) 
during pregnancy. 1 case of Graves' disease who was also having GDM underwent thyroidectomy in second trimester with supplementation of thyroxine due to intolerable tachycardia as radio isotope was contraindicated and family was reluctant for propranolol because of its side effect.

\section{Post-partum status}

Among the 79 hypothyroid mothers, 40 mothers continued to take pregnancy dose of thyroxine in whom post-partum thyroid function was not done neither at 6weeks nor later. Among them 22 were pre-pregnancy hypothyroid and 18 were hypothyroid during pregnancy. Other 39 mothers who stopped taking thyroxine and whom thyroid function test was not done (Figure 2).

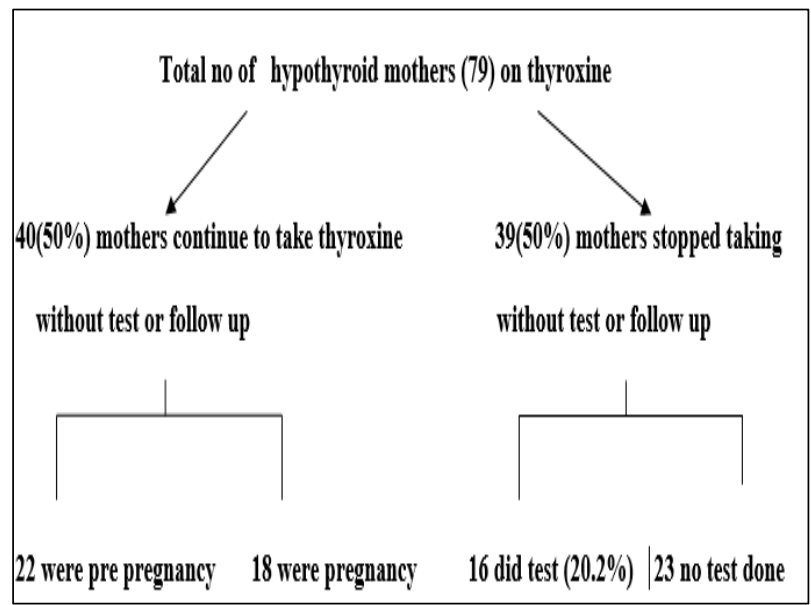

Figure 2: Post-partum hypothyroid status.

Among them 16 mothers were convinced to do the test by 14 weeks. In which 6 were pre pregnant and 10 were during pregnancy.

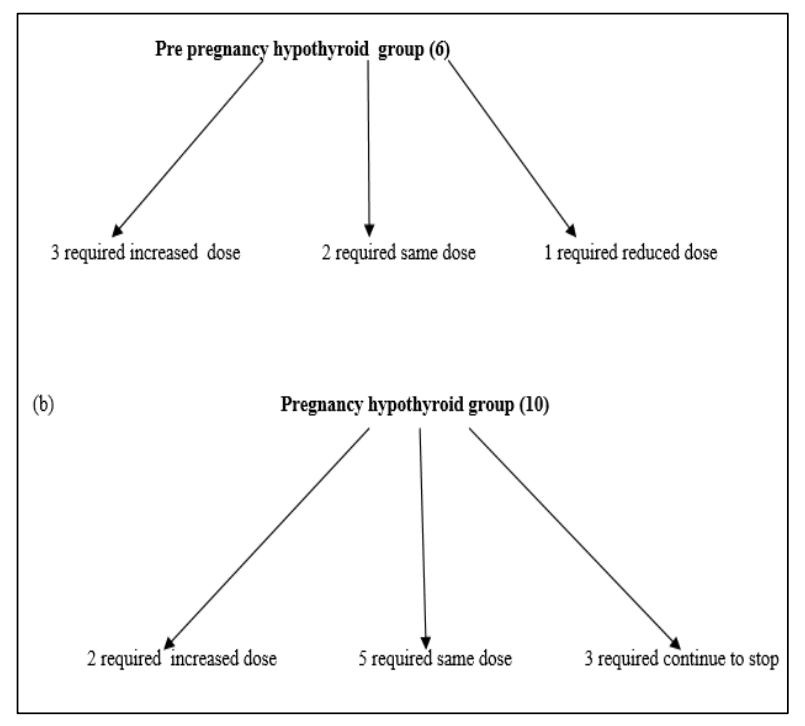

Figure 3: Post-partum requirement of thyroxine who stopped after thyroid function test in 16 mothers.
As per the advice of the endocrinologist, in the pre pregnancy group 3 require increased dose, same dose in 2 cases, and reduced dose in 1case. In the pregnancy group 2 required increased dose, 5 continuation of same dose and in 3 case advised to continue to stop as thyroid function was normal, who were on $25 \mathrm{mcg}$ of thyroxine during pregnancy (Figure $3 \mathrm{a}$ and $\mathrm{b}$ ).

In the hyperthyroid mother postnatal follow up documents were not available.

\section{New-born status}

In the babies of hypothyroid mother, new born screening for thyroid function was done in 14 (17.7\%) cases between 5-10 days. Preterm and low birth weight was found in 2 babies, neonatal hyperbilirubinemia in 7 cases of them 3 cases were receiving thyroxine $25 \mathrm{mcg}$. Case 1 : TSH-15 mIU/L, mother -primary infertility on thyroxine $50 \mathrm{mcg}$ pre pregnancy, pregnancy and post-natal period, case 2-TSH-6.25mIU/L, mother-pre-pregnancy hypothyroid with leg swelling was on $100 \mathrm{mcg}, 125 \mathrm{mcg}$ pregnancy, post-partum TSH-0.03 and levothyroxine reduced to $100 \mathrm{mcg}$.

TSH-9.215 mIU/L, mother- was on $25 \mathrm{mcg}$ thyroxine during pregnancy and post- partum. All these babies on subsequent visits TSH was lowered and higher T3 and T4 values and thyroxine was stopped and subsequently thyroid function test was normal. 1case was having CHD, ASD with minimal pericardial effusion, whose day5 TSH $-6.2 \mathrm{mI} \mathrm{U} / \mathrm{L}$, which repeated 6weeks was $3.13 \mathrm{mIU} / \mathrm{L}$. Mother of that case was having pre pregnancy hypothyroidism due to leg swelling and was on $75 \mathrm{mcg}$ of thyroxine pre pregnancy, pregnancy and postnatal period was also having GDM. By $3^{\text {rd }}$ dose of routine immunization which is at 14 weeks other 28 babies $(35.45 \%)$ babies got screened and 37 (46.83\%) babies still remained unscreened (Figure 4).

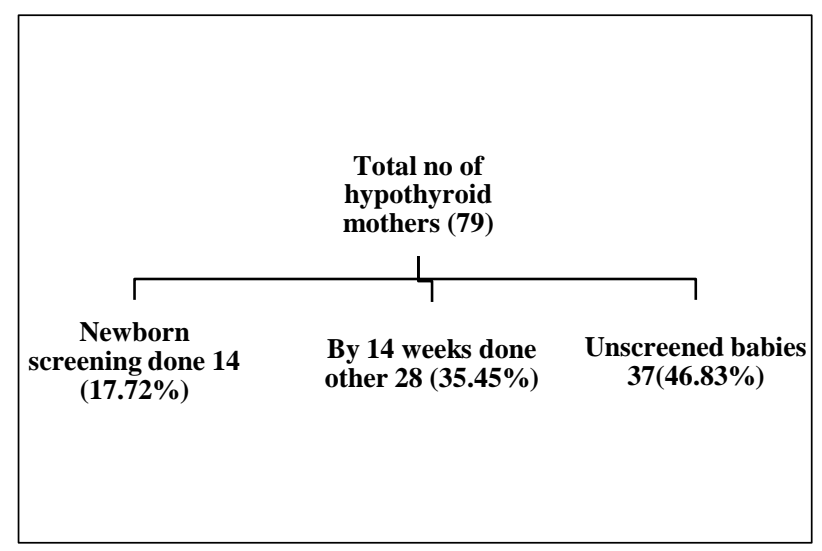

Figure 4: Thyroid screening status of the babies.

Authors did not find any features of congenital hypothyroidism in any baby clinically. In the babies of hyperthyroid mothers, in 5cases authors did not find any postnatal follow documents at 6 weeks and lost follow up 
in subsequent visit. New-born screening was done in 1 case, in which TSH was $0.03 \mathrm{mI} \mathrm{U/L.} \mathrm{At} \mathrm{3-month} \mathrm{thyroid}$ function was normal.

\section{DISCUSSION}

\section{Hypothyroidism}

All mothers had undergone universal screening for thyroid disorders in pregnancy. In pre pregnant group the thyroid function test was not clear most of them advised to continue same dose. Out of 32 pre-pregnant mothers 6 required increased dose, 6 required decreased dose and 20 continued with same dose. Majority of pre pregnant mothers were having thyroxine more than $50 \mathrm{mcg} / \mathrm{d}$. Total pregnancy related events were found in $33 \%$ of the mothers. Previous studies done in UK and also in India advocate for universal screen being better so that will not miss any mother with hypothyroidism thus preventing adverse maternal and fetal outcome. ${ }^{15,16}$ Thyroid screening is too an universal policy for women undergoing for IVF. ${ }^{17}$ Regarding thyroid autoimmunity in pregnancy the study done by Jayaraman et al, They found irrespective of thyroid autoimmunity status there was no difference in adverse pregnancy outcome of subclinical hypothyroid mother targeting TSH in euthyroid range. ${ }^{18}$ In none of our case thyroid autoimmunity was studied, treatment were based on TSH value. Previous guideline too recommended giving thyroxine irrespective of their antibody status. ${ }^{12}$ American thyroid association 2017 updated thyroxine should be given antithyroid antibody positive with initial $\mathrm{TSH} 2.5-425 \mathrm{mIU} / \mathrm{L}$. If the initial TSH is $425 \mathrm{mIU} / \mathrm{L}$ or more, thyroxine to be started irrespective of antibody status. ${ }^{13}$

Limited prospective study was based are on postpartum management of the hypothyroid mother. One of the important studies was done by Alex Stagnaro-green on post-partum management of women begun on levothyroxine during pregnancy had addressed this issue basing on various principles of thyroid function in pregnancy and postpartum.

In which they have suggested higher the TSH value during pregnancy, higher the levothyroxine dose requirement during pregnancy, thyroid antibody positivity, postpartum thyroiditis will require continuation of levothyroxine in post-partum. ${ }^{19}$

This has been observed in other studies which was done to know the natural course of subclinical hypothyroidism in post-partum period and beyond. The development of overt hypothyroidism $(\mathrm{OH})$ in Haddow et al, on 10 years follow up was $64 \%$, Shield BM et al, in their 5 year follow up was $25 \%$ and Indian study too in their 2 years follow up showed $18 \% .^{20,21,22}$

In present study though the number was less but authors support the similar factors in which post-partum requirement of thyroxine was there. European thyroid association guideline recommended discontinuation of thyroxine on antibody negative woman and check the TSH at $6^{\text {th }}$ weeks postpartum. ${ }^{12}$ Surprisingly authors did not find any postpartum thyroid function follow up plan in mother's discharge summary neither in public sector nor in private sector. Only 8 cases in public sector and 2 case in private sector had mentioned maternal hypothyroidism in primary diagnosis and all were pre pregnancy state. Only 2 cases in the public sector has been referred to endocrinologist for further management of hypothyroidism. All cases of hyperthyroidism mother were under follow up by the endocrinologist. Previous Indian study had already showed the burdening of Indian obstetric care with poor partum follow up and early unplanned pregnancy. ${ }^{23}$

In the post-partum period American thyroid association strongly recommends following delivery, patient's levothyroxine should be reduced to preconception dose and thyroid function testing should be performed at approximately 6 weeks postpartum.

However, there is weak evidence regarding continuation of same in women specially that group levothyroxine was initiated during pregnancy in whom the dose was $\leq 50 \mathrm{mcg} / \mathrm{d}$. The decision to discontinue if desired should be made by the patient and the caregiver and serum should be evaluated in approximately 6weeks.If woman had thyroid antibody positive and TSH less than 4 $\mathrm{mIU} / \mathrm{L}$, thyroxine can be ceased and thyroid function test at 6 weeks and if TSH more than $4 \mathrm{mIU} / \mathrm{L}$ then continue thyroxine. When thyroid antibody is negative but TSH is greater than $4 \mathrm{mIU} / \mathrm{L}$ thyroxine to be ceased thyroid function at $6^{\text {th }}$ weeks. ${ }^{13}$

\section{Hyperthyroidism}

Both hypothyroidism and hyperthyroidism can occur in subclinical state. The prevalence of overt hyperthyroidism in pregnancy is of $0.1-0.4 \%$. Graves' disease account for $85 \%$, followed by HCG mediated gestational transient thyrotoxicosis which is limited to first half of the pregnancy. ${ }^{8}$ Less common nonautoimmune cause are toxic multinodular goiter and toxic adenoma.Very rare cause is thyroid secreting pituitary adenoma, struma ovarii, functional thyroid cancer metastasis or germline TSH receptor mutations. Though the number was less, we find similar $0.16 \%$ of cases of hyperthyroidism. Graves' disease too likely to be most important cause. Over treatment or factitious intake of thyroid hormone remains a special cause for hyperthyroidism. ${ }^{13}$ Country like us in which the pre pregnancy follow up is poor and post-partum follow is still more poor, we should focus on this over treatment of thyroid hormone group.

\section{Post -partum issues noticed}

- In most cases especially in those hypothyroidisms diagnosed related to previous pregnancy issues like 
primary infertility or pregnancy loss take it over as the present pregnancy went well and thyroxine is not required

- In the subclinical hypothyroidism cases in present pregnancy some of them thought as pregnancy is over no need of continuation

- In others as thyroxine was started in like calcium and iron medication in pregnancy, they decided to continue this for few months post-partum along with calcium and iron

- Though in all cases, postpartum follow up was mentioned at 6weks in the discharge summary, they were ignorant about it as it was restricted to papers as formalities to get discharged. No verbal communication was found both in private as well as public sector. As the pregnancy was over mothers do not feel the requirement of it

- Mothers were completely ignorant about post-partum period and long-term future consequences on them and on the babies

- Many mothers and family were also reluctant to go to the endocrinologist a new specialist in post-partum period as the pregnancy went well and they are physically normal

- We tried to make them understand along with the family. So, the postpartum tests depicted in the postpartum mother or post-natal babies were done only after the counselling

To solve all these issues, authors suggest joint obstetricendocrinologist coordination in pregnancy and after the pregnancy is over follow up with endocrinologist can be done comfortably.

\section{Postnatal status}

Congenital hypothyroidism $(\mathrm{CH})$ is the most common treatable cause of mental retardation. It can be caused by thyroid dysgenesis, disorder of thyroid hormone synthesis, iodine deficiency or excess, as well as transplacental transfer of maternal antibodies or medications. ${ }^{24}$ There is plenty of evidence that untreated maternal hypothyroidism leading to preterm birth, low birth weight, respiratory distress and fetal brain. ${ }^{4}$ Even mild hypothyroidism can interfere with normal brain development. ${ }^{3}$ Meta-analysis done by Derksen- Lubsen G et al, suggested at least part of the brain damage in patients with $\mathrm{CH}$ occurred in utero and may not be prevented by initiation of early treatment after birth. ${ }^{25}$ In present study in majority of case newborn screening was not done. By $14^{\text {th }}$ weeks authors were able to do thyroid function test only half of the babies.

During follow up all babies were normal. Practically none of the babies required supplementation of thyroxine by $14^{\text {th }}$ week. Including the babies 3 babies in whom throxine was given for short period. In such cases the TSH was between 6.25-15 mI U/L between 5-10days of life. As the babies were having neonatal hyperbilirubinemia the threshold for treating with throxine was low. Studies done abroad and also in India suggest avoidance of requirement of thyroxine in the babies by early detection and initiation of therapy in pregnancy. ${ }^{16,26,27}$ All newborns should be screened for hypothyroidism and the aetiology, severity, treatment of maternal thyroid disease should be documented in the newborn baby's medical record. At times direct communication to the pediatrician or the neonatologist is required in maternal hyperthyroidism and in use of antithyroid drugs, ideally before birth. ${ }^{13}$

At present authors do not have national newborn screening program (NBS) in India. Physicians were following existing guidelines by different professional bodies. Recently Indian society of pediatric and adolescent endocrinology (ISPAE) in 2018 formulated guidelines and recommends till NBS is integrated in national health programmed in India, pediatricians and health authorities should make concerted efforts to initiate NBS for $\mathrm{CH}$ for all in their care. ${ }^{28,29}$

The guideline is very much clear regarding the screening, confirmation of diagnosis, imaging, treatment and follow up. Newborn should be screened for $\mathrm{CH}$ by cord blood or day 3 to day 5 postnatal venus blood either serum or dried blood spot (DBS). Primary TSH based $\mathrm{CH}$ screening is more practical and cost effective in our scenario. Comparing with our newborn screening and treatment follow up status, authors suggest our pediatrician and neonatologist to be familiar with it.

Limitation of the study were our center being a main medical hub of the state, many families have short stay only for the process of delivery or few weeks postpartum stay in their relative's house who were likely to be missed from the study during follow up. So, there is likely underestimation of the real-life burden. In none of our cases TPOAb testing was done and treatment were based on TSH values. In many mothers' authors were able to collect the treatment with thyroxine documents, but thyroid function reports were not available.

\section{CONCLUSION}

Thyroid screening should be done in pregnancy as universal screening instead of high-risk cases.

Documentation and interdepartmental coordination are very much essential in thyroid disorders, for further decision by the physician for necessity of continuation of treatment and thyroid function test in the post-partum period for the mothers and its long-term consequences. It also guides the neonatologist or paediatrician doing thyroid function test of their babies. Ideally All newborns should be screened for congenital hypothyroidism as a part of new born screening (NBS) programme. Effective communication with the mother and the family is very much essential for monitoring and treatment of both mother and the baby. 
Funding: No funding sources

Conflict of interest: None declared

Ethical approval: Not required

\section{REFERENCES}

1. Burrow GN, Fisher DA, Larsen PR. Maternal and fetal thyroid function. New Eng $\mathrm{J}$ Med. 1994;331(16):1072-8.

2. Sahay RK, Nagesh VS. Hypothyroidism in pregnancy. Indian $\mathrm{J}$ Endocrinol Metabol. 2012;16(3):364.

3. Fan $\mathrm{X}, \mathrm{Wu} \mathrm{L}$. The impact of thyroid abnormalities during pregnancy on subsequent neuropsychological development of the offspring: a meta-analysis. J Maternal Fetal Neonat Med. 2016;29(24):3971-6.

4. Maraka S, Mwangi R, McCoy RG, Yao X, Sangaralingham LR, Ospina NM, et al. Thyroid hormone treatment among pregnant women with subclinical hypothyroidism: US national assessment. BMJ. 2017;356:i6865.

5. Chen LM, Du WJ, Dai J, Zhang Q, Si GX, Yang H. Effects of subclinical hypothyroidism on maternal and perinatal outcomes during pregnancy: a singlecenter cohort study of a Chinese population. PloS One. 2014;9(10):e109364.

6. Krassas GE, Poppe K, Glinoer D. Thyroid function and human reproductive health. Endocrine Reviews. 2010;31(5):702-55.

7. Smallridge RC, Ladenson PW. Hypothyroidism in pregnancy: consequences to neonatal health. J Clinic Endocrinol Metabol. 2001;86(6):2349-53.

8. Lazarus JH. Thyroid function in pregnancy. British Med Bull. 2011;97:137-48.

9. Stagnaro-Green A, Abalovich M, Alexander E, Azizi F, Mestman J, Negro R, et al. Guidelines of the American thyroid association for the diagnosis and management of thyroid disease during pregnancy and postpartum. Thyroid. 2011;21(10):1081-125.

10. De Groot L, Abalovich M, Alexander EK, Amino N, Barbour L, Cobin RH, et al. Management of thyroid dysfunction during pregnancy and postpartum: an Endocrine Society clinical practice guideline. J Clinic Endocrinol Metabol. 2012;97(8):2543-65.

11. Garber JR, Cobin RH, Gharib H, Hennessey JV, Klein I, Mechanick JI, et al Woeber for the American Association of Clinical Endocrinologists and American thyroid association taskforce on hypothyroidism in adults KA. Clinical practice guidelines for hypothyroidism in adults: cosponsored by the American association of clinical endocrinologist and American thyroid association. Endocr Pract .2012; 18:988-1028.

12. Lazarus J, Brown RS, Daumerie C, HubalewskaDydejczyk A, Negro R, Vaidya B, 2014 European thyroid association guidelines for the management of subclinical hypothyroidism in pregnancy and in children. Eur Thyroid J. 2014;3:76-94.

13. Alexandar EK, Pearce EN, Brent GA, Brown RS, Chen H, Dosiou C, et al, 2017 Guideline of
American thyroid association for the diagnosis and management of thyroid disease during pregnancy and postpartum. Thyroid. 2017;27:315-89.

14. Smith A, Eccles- Smith J, D’Emden M, Lust K, Thyroid disorders in Pregnancy and Postpartum. Aust Prescr. 2017;41:214-9.

15. Dave A, Maru L, Tripathi M. Importance of Universal screening for thyroid disorders in first trimester of pregnancy. Indian J Endocrinol Metabol. 2014;18(5):735.

16. Taylor P, Lacey A, Thayer D, Draman M, Tabasum A, Muller I, et al Controlled antenatal thyroid screening study (CATS). N Engl J Med. 2012; 366:493-501.

17. Mintziori G, Goulis DG, Kolibianakis EM. Thyroid function and IVF outcome: when to investigate and when to intervene?. Current Opinion Obstet Gynecol. 2016;28(3):191-7.

18. Jayaraman M, Verma A, Harikumar KV, Ugale M, Modi K. Pregnancy outcomes with thyroxine replacement for subclinical hypothyroidism: Role of thyroid autoimmunity. Indian J Endocrinol Metabol. 2013;17(2):294.

19. Stagnaro-Green A. Postpartum management of women begun on levothyroxine during pregnancy. Front Endocrinol (Lausanne). 2015;6:183.

20. Haddow JE, Palomaki GE, Allan WC, Williams JR, Knight GJ, Gagnon J, et al. Maternal thyroid deficiency during pregnancy and subsequent neuropsychological development of the child. New Eng J Med. 1999;341(8):549-55.

21. Shields BM, Knight BA, Hill AV, Hattersley AT, Vaidya B. Five-year follow-up for women with subclinical hypothyroidism in pregnancy. J Clinic Endocrinol Metabol. 2013;98(12):E1941-5.

22. Neelaveni K, Kumar KH, Sahay R, Ramesh J. Postpartum follow-up in women diagnosed with subclinical hypothyroidism during pregnancy. Indian J Endocrinol Metabol. 2017;21(5):699.

23. Pandey A, Das V, Agarwal A, Agrawal S, Misra D, Jaiswal N. Evaluation of obstetric near miss and maternal deaths in a tertiary care hospital in north India: shifting focus from mortality to morbidity. J Obstet Gynecol of India. 2014;64(6):394-9.

24. Ozdemir H, Akman I, Coskun S, Demirel U, Turan $\mathrm{S}$, Bereket A, et al. Maternal thyroid dysfunction and neonatal thyroid problems. Int $\mathbf{J}$ Endocrinol. 2013;2013.

25. Derksen-Lubsen G, Verkerk PH. Neuropsychologic development in early treated congenital hypothyroidism: analysis of literature data. Pediat Res. 1996;39(3):561.

26. Ogundele MO, Waterson M. When should we be conducting thyroid function tests in newborns and young infants? Arch Dis Childhood. 2010;95(2):151-2.

27. Shravani MR, Tharashree CD, Yashodha HT. Maternal hypothyroidism and neonatal outcome. Int J Contemp Pediatr.2018;5(2):600-4. 
28. Desai MP, Sharma R, Riaz I, Sudhanshu S, Parikh R, Bhatia V. Newborn screening Guidelines for congenital hypothyroidism in India: recommendations of the Indian society for pediatric and adolescent endocrinology (ISPAE) - Part I: screening and confirmation of diagnosis. Indian $\mathrm{J}$ Pediat. 2018;85(6):440-7.

29. Desai MP, Sharma R, Riaz I, Sudhanshu S, Parikh R, Bhatia V. Newborn screening guidelines for congenital hypothyroidism in India: recommendations of the Indian society for pediatric and adolescent endocrinology (ISPAE)-Part I: screening and confirmation of diagnosis. Indian $\mathbf{J}$ Pediat. 2018;85(6):440-7.

Cite this article as: Das B, Khuntia P. Thyroid disorder in pregnancy and postpartum with neonatal outcome a study in tertiary care centre. Int J Reprod Contracept Obstet Gynecol 2019;8:1795-801. 